DOI: $10.7242 / 2658-705 X / 2019.3 .5$

УДК 528.94

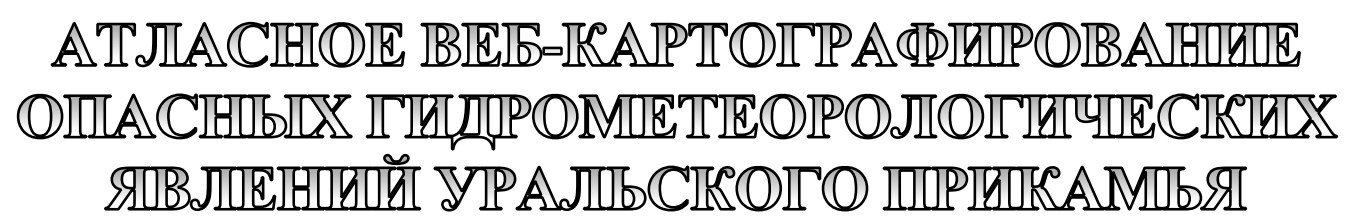

А.Н. Шихов, Пермский государственный национальный исследовательский университет

Р.К. Абдуллин, Пермский государственный национальный исследовательский университет

Представлен опыт проектирования и разработки атласной информационной системы (АИС) опасных гидрометеорологических явлений (ОГМЯ) Уральского Прикамья. АИС создана на основе синтеза классических подходов в области атласного картографирования и современных технологий разработки картографических веб-сервисов. Рассмотрена ее информационная основа, включающая несколько источников данных как наземных, так и дистанционных наблюдений. Кратко описаны основные методические приемы и алгоритмы, разработанные для создания карт пространственно-временного распределения ОГМЯ и информационного наполнения АИС. Представлены примеры созданных карт повторяемости и интенсивности различных видов ОГМЯ, а также результаты зонирования территории Пермского края по преобладающим видам опасных явлений погоды. Рассмотрены основные функциональные возможности АИС, включающие различные способы визуализации данных, подключение к внешним базам данных, поиск и формирование запросов, построение картограмм и структурных диаграмм.

АИС опубликована в открытом доступе в виде картографического вебсервиса (http://ais.maps.psu.ru). Для Пермского края основным результатом проекта является создание уникального справочно-информационного ресурса о современных климатических условиях региона и характерных для региона видах ОГМЯ, а также их негативных последствиях.

Ключевые слова: опасные гидрометеорологические явления, атласное картографирование, атласная информационная система, Уральское Прикамье.

\section{Введение}

Согласно классическому определению, «атлас - это систематическое собрание географических карт, выполненное по общей программе как целостное произведение» [6]. С момента появления атласы прошли длительный путь своего развития. Благодаря внедрению ГИС-технологий и развитию геоинформационного картографирования появились электронные атласы, отличающиеся интерактивностью и большими функциональными возможностями для работы с картами, по сравнению с традиционными атласами.

\footnotetext{
* Статья подготовлена при финансовой поддержке гранта РФФИ № 16-45-590056-р_а «Атласное веб-картографирование опасных гидрометеорологических явлений Уральского Прикамья».
} 
Высшим типом электронных атласов являются интерактивные атласные информационные системы [7]. Под атласной информационной системой (АИС) понимают информационную систему, созданную для определенной территории или по определенной тематике, где доминирующую роль играют карты и в которой для пользователей имеются дополнительные возможности по составлению картографических изображений [12]. АИС обладает свойствами всех типов электронных атласов: от простой визуализации до возможностей пространственно-статистического анализа данных, расширенного моделирования, составления карт и геоизображений с применением широкого набора изобразительных средств. Спектр тематических направлений создания АИС достаточно широк. В качестве примеров можно привести АИС поддержки устойчивого развития территорий [9], АИС управления природопользованием в Байкальском регионе [7], демографическую АИС России [8], АИС Азиатской России [4].
Атласы и АИС являются также важным инструментом для оценки территориального риска чрезвычайных ситуаций (ЧС) природного характера, снижения потенциального ущерба от них и поддержки принятия решений. Это подтверждается примерами таких работ, как «Мировой атлас опасных природных явлений» [13], «Атлас природных и техногенных опасностей и рисков в РФ» [3] и др. На кафедре картографии и геоинформатики Пермского государственного национального исследовательского университета в 2016 г. был подготовлен и издан «Атлас опасных гидрометеорологических явлений (ОГМЯ) Уральского Прикамья» [5]. Логическим продолжением данной работы стало создание электронной версии атласа - АИС ОГМЯ Уральского Прикамья.

\section{Исходные данные}

Массив данных об ОГМЯ, представляющий собой информационную основу создания АИС (таблица), сформирован путем интеграции нескольких источников на-

Информационная основа АИС «ОГМЯ Уральского Прикамья»

Таблицุа

\begin{tabular}{|c|c|c|}
\hline Тип данных & Источник данных & Получаемые данные для АИС \\
\hline \multicolumn{3}{|c|}{ Базовые пространственные данные } \\
\hline $\begin{array}{c}\text { Цифровая векторная } \\
\text { карта масштаба } \\
\text { 1:1000 } 000 \\
\end{array}$ & Роскартография & $\begin{array}{c}\text { Формирование базового набора } \\
\text { пространственных данных. }\end{array}$ \\
\hline \multicolumn{3}{|c|}{ Тематические данные } \\
\hline $\begin{array}{c}\text { Данные сети } \\
\text { метеостанций и } \\
\text { гидрологических постов } \\
\text { Пермского ЦГМС }\end{array}$ & $\begin{array}{c}\text { Метеорологические ежемесячники и } \\
\text { ежегодники, данные ВНИИГМИ-МЦД, } \\
\text { Интернет-ресурсы, ГИС «Бассейн } \\
\text { Воткинского водохранилища» }\end{array}$ & $\begin{array}{c}\text { Данные о случаях ОГМЯ, зафиксированных } \\
\text { наблюдательной сетью для наполнения базы } \\
\text { данных (http://map.psu.ru/search.aspx); } \\
\text { режимные климатические характеристики } \\
\text { для создания соответствующих карт }\end{array}$ \\
\hline $\begin{array}{c}\text { Данные об ОГМЯ } \\
\text { и нанесенном ими } \\
\text { ущербе, полученные } \\
\text { от очевидцев и СМИ }\end{array}$ & $\begin{array}{c}\text { Отчеты Пермского ЦГМС по } \\
\text { результатам обследований в случаях } \\
\text { ОГМЯ, нанесших ущерб; база данных } \\
\text { ESWD (European Severe Weather } \\
\text { Database) - http://www.eswd.eu } \\
\end{array}$ & $\begin{array}{c}\text { Данные о случаях ОГМЯ и ущербе от них для } \\
\text { наполнения базы данных } \\
\text { (http://map.psu.ru/search.aspx) и создания } \\
\text { карты повторяемости локальных } \\
\text { конвективных явлений } \\
\end{array}$ \\
\hline $\begin{array}{c}\text { Данные об опасных } \\
\text { явлениях, нанесших } \\
\text { социальный } \\
\text { и экономический ущерб } \\
\text { на территории России }\end{array}$ & $\begin{array}{c}\text { База данных ГУ «ВНИИГМИ-МЦД»- } \\
\text { http://meteo.ru/data/310- } \\
\text { neblagopriyatnye-usloviya-pogody- } \\
\text { nanjosshie-ekonomicheskie-poteri }\end{array}$ & То же \\
\hline $\begin{array}{c}\text { Данные реанализа } \\
\text { NCEP/NCAR, CFSv2 } \\
\text { и GDAS. }\end{array}$ & Открытые сервисы NOAA & $\begin{array}{c}\text { Карты синоптических условий возникновения } \\
\text { ОЯ в виде графических файлов для } \\
\text { наполнения базы данных } \\
\text { (http://map.psu.ru/search.aspx) }\end{array}$ \\
\hline
\end{tabular}




\begin{tabular}{|c|c|c|}
\hline & & Окончание таблицы \\
\hline Тип данных & Источник данных & Получаемые данные для АИС \\
\hline $\begin{array}{c}\text { Данные об опасных } \\
\text { конвективных явлениях }\end{array}$ & $\begin{array}{c}\text { Архивные данные } \\
\text { метеорологического радиолокатора } \\
\text { МРЛ-5 (г. Пермь, с } 1996 \text { г.) и ДМРЛ } \\
\text { Ижевск (с } 2014 \text { г.) по случаям } \\
\text { опасных конвективных явлений }\end{array}$ & $\begin{array}{c}\text { Карты метеоявлений и высоты верхней } \\
\text { границы облаков (ВГО) по данным ДМРЛ } \\
\text { в момент возникновения опасного явления } \\
\text { для наполнения базы данных } \\
\text { (http://map.psu.ru/search.aspx) }\end{array}$ \\
\hline $\begin{array}{c}\text { Многолетний ряд } \\
\text { спутниковых данных } \\
\text { низкого разрешения } \\
\text { Terra/Aqua MODIS } \\
\text { с } 2001 \text { г. по настоящее } \\
\text { время }\end{array}$ & $\begin{array}{c}\text { Каталог NASA - } \\
\text { https://ladsweb.modaps.eosdis.nasa.gov }\end{array}$ & $\begin{array}{c}\text { Карты температуры ВГО для случаев } \\
\text { возникновения конвективных ОЯ для } \\
\text { наполнения базы данных } \\
\text { (http://map.psu.ru/search.aspx); } \\
\text { исходные данные для создания карты } \\
\text { повторяемости мезомасштабных } \\
\text { конвективных систем (МКС) }\end{array}$ \\
\hline $\begin{array}{c}\text { Продукт обработки } \\
\text { спутниковых данных } \\
\text { MODIS MOD14 (Thermal } \\
\text { Anomalies-Fires) } \\
\text { с } 2001 \text { г. по настоящее } \\
\text { время } \\
\end{array}$ & $\begin{array}{l}\text { Система мониторинга пожаров FIRMS } \\
\text { https://earthdata.nasa.gov/earth- } \\
\text { observation-data/near-real- } \\
\text { time/firms/active-fire-data }\end{array}$ & $\begin{array}{c}\text { Исходные данные для создания векторного } \\
\text { слоя крупных гарей в АИС (дополнительные } \\
\text { данные за 2001-2018 гг.) }\end{array}$ \\
\hline $\begin{array}{c}\text { Многолетний ряд } \\
\text { спутниковых данных } \\
\text { Landsat с } 1984 \text { г. } \\
\text { по настоящее время, } \\
\text { Sentinel-2 с } 2016 \text { г. } \\
\text { по настоящее время }\end{array}$ & $\begin{array}{c}\text { Каталог USGS - } \\
\text { https://earthexplorer.usgs.gov }\end{array}$ & $\begin{array}{l}\text { Исходные данные для создания } \\
\text { картографических слоев в АИС: } \\
\text { • крупные лесные пожары } \\
\text { • крупные ветровалы } \\
\text { • зоны потенциального затопления } \\
\text { в поймах рек }\end{array}$ \\
\hline $\begin{array}{c}\text { Результаты } \\
\text { моделирования зон } \\
\text { возможного затопления, } \\
\text { фотоматериалы } \\
\end{array}$ & $\begin{array}{c}\text { Фондовые материалы } \\
\text { ГИС-центра ПГНИУ }\end{array}$ & $\begin{array}{c}\text { Картографические слои зон возможного } \\
\text { затопления населенных пунктов, } \\
\text { опубликованные в АИС }\end{array}$ \\
\hline $\begin{array}{c}\text { Данные о лесных } \\
\text { пожарах по } \\
\text { результатам наземного } \\
\text { мониторинга } \\
\text { и авиапатрулирования } \\
\text { за период с } 2008 \text { г. } \\
\text { по настоящее время }\end{array}$ & $\begin{array}{l}\text { Министерство природных } \\
\text { ресурсов Пермского края }\end{array}$ & $\begin{array}{c}\text { Источник данных для картографического } \\
\text { слоя «Лесные пожары» }\end{array}$ \\
\hline $\begin{array}{c}\text { Данные реанализа } \\
\text { NCEP/NCAR, CFSv2 } \\
\text { и GDAS. }\end{array}$ & Открытые сервисы NOAA & $\begin{array}{c}\text { Карты синоптических условий возникновения } \\
\text { ОЯ в виде графических файлов для } \\
\text { наполнения базы данных } \\
\text { (http://map.psu.ru/search.aspx) }\end{array}$ \\
\hline
\end{tabular}

земных и дистанционных данных, различающихся продолжительностью наблюдений, а также пространственным и временным разрешением. Для систематизации, интеграции и хранения разнородной информации об ОГМЯ создана картографическая база данных под управлением СУБД PostgreSQL.

\section{Методы картографирования характеристик ОГМЯ}

Для тематического наполнения АИС разработан комплекс методических приемов и алгоритмов картографирования пространственно-временного распределения ОГМЯ на региональном уровне [1, 2]. Разработанные алгоритмы направлены на устранение проблем, возникающих при картографировании ОГМЯ на региональном уровне вследствие дефицита исходной информации, неоднократного изменения критериев опасных явлений, пропуска наблюдательной сетью явлений локального характера. На основе данных приемов и алгоритмов построены карты режимных характеристик опасных явлений и синтетические карты, представленные в АИС. 
Пространственно-временное распределение ОГМЯ можно рассматривать как повторяемость (число случаев за период времени), а также как плотность (число случаев на единицу площади за период времени). Для явлений, характеризующихся значительным охватом территории (экстремальная температура воздуха, сильные осадки и др.), по данным сети метеостанций оценивается повторяемость, а также средняя и максимальная интенсивность. Для локальных явлений конвективного характера (шквалы, крупный град, смерчи) на мелких масштабах оценивается плотность пространственного распределения случаев, которые рассматривались как точечные события. В качестве исходной информации для таких карт используются данные наблюдательной сети, а также информация об ущербе, данные космической съемки и продукты их обработки.

Методика создания карт режимных характеристик опасных явлений погоды (ОЯП) на основе данных наблюдательной сети описана в работе [1]. В основе построения карт повторяемости и интенсивности ОЯП на региональном уровне лежит интерполяция данных наблюдательной сети с учетом регрессионных зависимостей от свойств подстилающей поверхности (высоты местности, уклона, экспо- зиции и общей кривизны склонов). Выбор данного подхода обусловлен наличием в пределах исследуемой территории возвышенностей и гор, которые оказывают значительное влияние на распределение основных климатических характеристик, в том числе на повторяемость экстремальных метеорологических явлений. Примеры использованных зависимостей и созданных карт приведены на рис. 1, 2.

Для локальных конвективных явлений (шквалы, крупный град, смерчи) вместо повторяемости оценивалась плотность пространственного распределения (за 2001-2016 гг.). Места фиксации явлений представлены в виде точек, с указанием числа случаев за рассматриваемый период. Всего получены сведения о 40 случаях шквалов, 6 смерчах и 12 случаях крупного града, которые произошли в Пермском крае в период с 2001 по 2016 г. Расчет плотности точечных объектов производился с помощью алгоритма плотности ядер (Kernel Density) модуля Spatial Analyst программного продукта ArcGIS. Аналогичная методика, основанная на оценке плотности точечных объектов, используется для картографирования пространственного распределения случаев смерчей на территории США [10] и Европы [11].

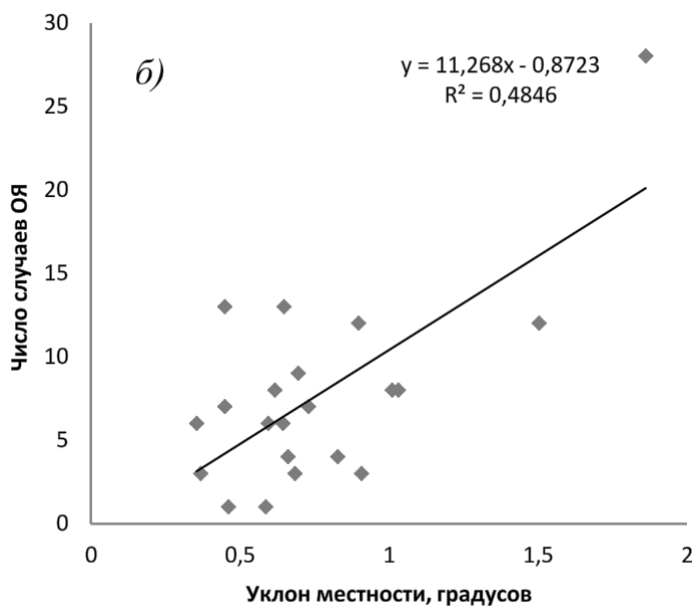

Рис. 1. Примеры зависимостей, использованных при построении карт режимных характеристик опасных явлений погоды: а - зависимость числа случаев сильных морозов от общей кривизны склонов, б - зависимость числа случаев сильных снегопадов от пересеченности рельефа 

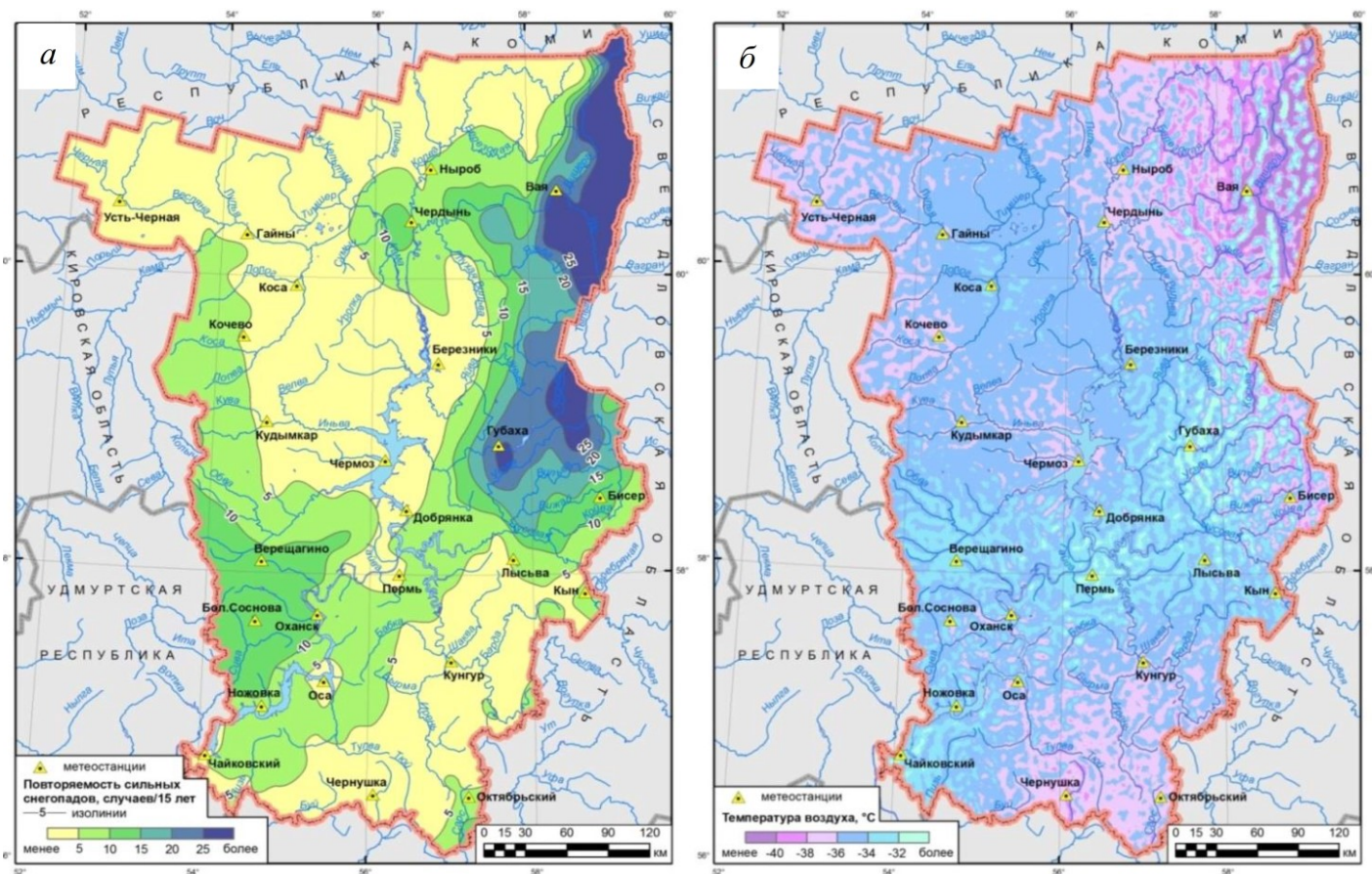

Рис. 2. Карты режимных характеристик опасных явлений погоды (а-повторяемость сильных снегопадов, б-среднегодовой минимум температуры воздуха)

При расчете плотности также учитывалась зависимость числа зафиксированных конвективных ОЯП от плотности сети наблюдений. Коэффициент линейной корреляции Пирсона между этими величинами равен 0,63 . Плотность пространственного распределения конвективных ОЯ была приведена к максимальной по территории региона плотности наблюдательной сети (2,55 пунктов / 1000 км2). Полученная карта приведена на рис. 3 .

Недостатком описанного подхода к оценке повторяемости конвективных ОЯП является, прежде всего, разнородность исходных данных и случайный характер фиксации явлений по данным об ущербе (которые составляют почти треть от всех рассмотренных случаев). В отличие от данных об ущербе, представленных в отчетах Пермского ЦГМС, данные наблюдений метеостанций, а также данные о ветровалах, полученные на основе снимков Landsat, можно считать однородными.

На основе многолетних данных о случаях опасных метеорологических явлений в Пермском крае были также построены синтетические карты - карта интегральной оценки повторяемости климатических экстремумов и районирование территории по преобладающим

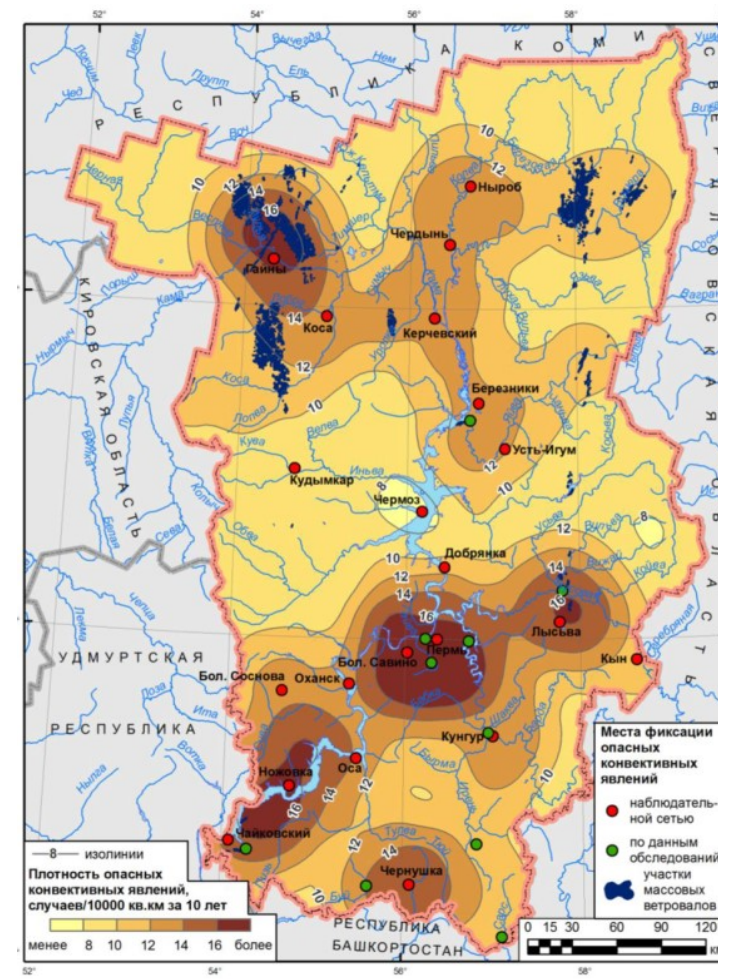

Рис. 3. Плотность пространственного распределения конвективных ОЯП за 2001-2016 г2. 
видам ОЯП (рис. 4). Методика их создания описана в работе [2].
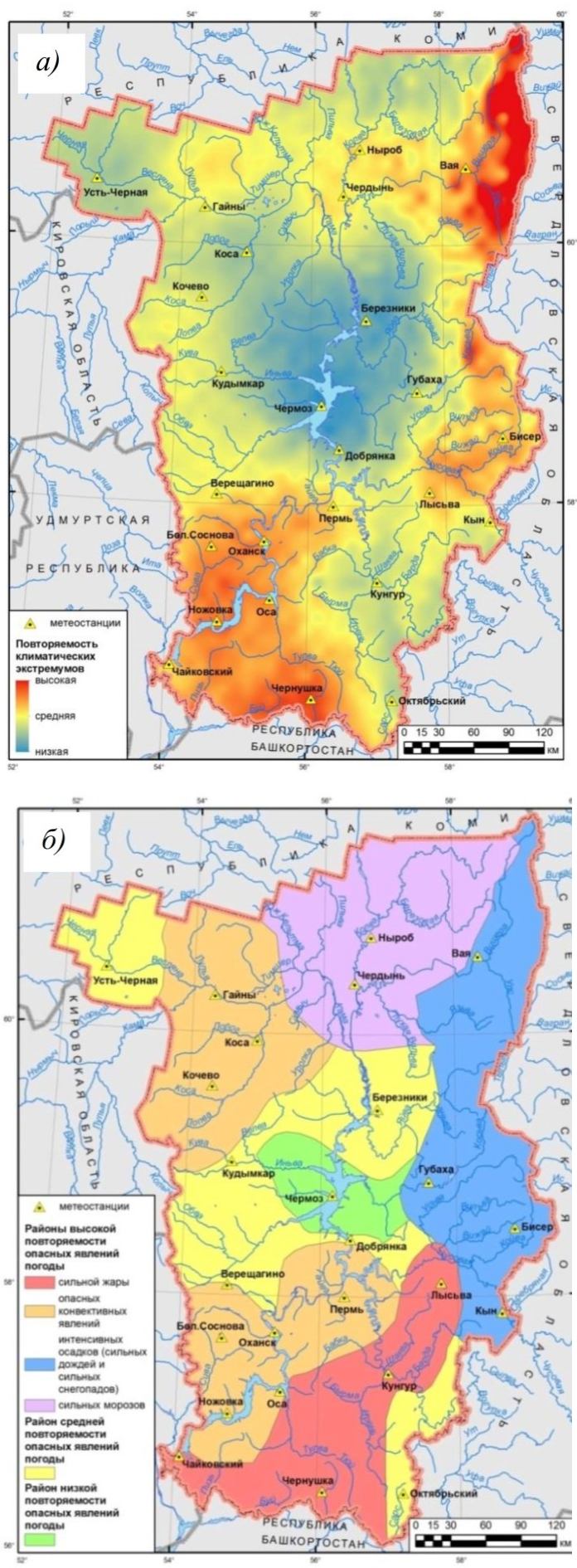

Рис. 4. Интегральная оченка повторяемости климатических экстремумов (a)

и районирование территории Пермского края по преобладающим видам ОЯП (б)

Из полученных карт можно сделать вывод, что в наиболее неблагоприятных условиях по повторяемости климатиче54 ских экстремумов находятся горные северо-восточные районы края, главным образом за счёт высокой повторяемости сильных дождей и снегопадов, а также (в меньшей степени) сильных морозов. Второй максимум повторяемости климатических экстремумов приурочен к южным и югозападным частям края. Его выделение связано с высокой повторяемостью сильной жары и конвективных опасных явлений (по юго-западным районам), а также с тем, что эти явления часто вызывают социально-экономический ущерб и при расчёте имели более высокий весовой коэффициент. При районировании экспертным методом был выявлен объективно существующий максимум повторяемости конвективных явлений в северо-западной части края, где зафиксировано большинство случаев смерчей. В центральных районах края вблизи Камского водохранилища ярко выражен минимум повторяемости климатических экстремумов.

\section{Содержание и функциональные возможности АИС ОГМЯ Уральского Прикамья}

Созданная база данных и серия карт различных характеристик ОГМЯ стала информационной основой АИС ОГМЯ Уральского Прикамья. Доступ к АИС реализован в виде веб-приложения, которое опубликовано в сети Интернет по адpecy http://ais.maps.psu.ru АИС обеспечивает получение комплексной пространственной характеристики различных видов ОГМЯ, наблюдающихся на территории Уральского Прикамья на основе регулярно обновляемых данных.

Интерфейс доступа к АИС реализован в виде картографического веб-сервиса. Для публикации пространственных данных в сети Интернет, а также организации доступа к ним пользователей применяется установленный на веб сервер ГИС-сервер ArcGIS Server 10.х, публикация данных выполняется из настольного программного обеспечения ArcGIS Desktop 10.x. Доступ пользователей АИС 
«ОГМЯ Уральского Прикамья» через сеть Интернет организован при помощи клиентского веб-приложения, реализованного на базе технологий HTML5, CSS3 и JavaScript. Руководство пользователя АИС доступно по ссылке http://ais.maps.psu.ru/help/help.html.

Основные функциональные возможности АИС

- Визуализация пространственного распределения ОГМЯ с применением различных способов картографического изображения.

- Визуализация статистических данных (многолетних рядов наблюдений, распределения типов ОГМЯ в пределах всей рассматриваемой территории и отдельных районов, а также по отдельным метеостанциям) с помощью структурных и столбчатых диаграмм.

- Основные инструменты навигации по карте, включая масштабирование изображения, поиск объектов на карте и визуализацию его результатов, картометрические средства (расчет расстояний и площадей).

- Доступ к атрибутивным данным, включая поиск данных о случаях ОГМЯ на территории региона из Базы данных опасных явлений погоды в Пермском крае (http://map.psu.ru/search.aspx) и Европейской базы данных опасных явлений погоды ESWD. Таким образом, в АИС ОГМЯ реализована интеграция со сторонними базами данных, как российскими, так и зарубежными.

Возможнности генерации новых картографических изображений, а именно картограмм (по муниципальным районам), а также динамических карт повторяемости и интенсивности опасных явлений по 5-летним временным интервалам (с 2001 г. по текущее время, с шагом в 1 год). Содержание АИС включает 6 разделов:

- климатический и гидрологический режим;

- режимные характеристики опасных явлений;

- базы данных опасных явлений;
- характерные случаи опасных явлений;

- негативные последствия опасных явлений;

- районирование и зонирование территории.

При включении некоторых тематических карт становятся доступными для просмотра также многолетние ряды данных наблюдений за соответствующими метеорологическими величинами по ряду метеостанций Пермского края. Пользователь имеет возможность визуализировать многолетние ряды климатических и гидрологических характеристик (с 1981 г. по настоящее время для метеостанций и с 1972 по 2002 г. для гидропостов) в виде графиков и диаграмм (рис. 5). На вкладке «Легенда» пользователю представлены условные обозначения отображаемой в окне тематической карты или базовой карты.

В разделе «Базы данных опасных явлений» реализован доступ к данным о зафиксированных случаях ОЯП на территории региона, а также информация об их негативных последствиях. При отображении мест фиксации ОЯП (метеостанций, гидропостов, населенных пунктов, участков массовых ветровалов) имеется возможность их идентификации и просмотра в табличной форме списка случаев за период с 1990 г. по текущее время в данном пункте (рис. 6). На основе данных об ОЯП и местах фиксации можно получать структурные диаграммы (см. 6) и картограммы (рис. 7), характеризующие соотношение различных видов ОЯП по метеостанциям, муниципальным образованиям региона, а также по всему Пермскому краю.

Для поиска и анализа данных созданы инструменты формирования атрибутивных запросов (выборки случаев опасных явлений по видам, временному периоду, местам фиксации, продолжительности и интенсивности).

На вкладке «Негативные последствия опасных явлений» представлены много- 


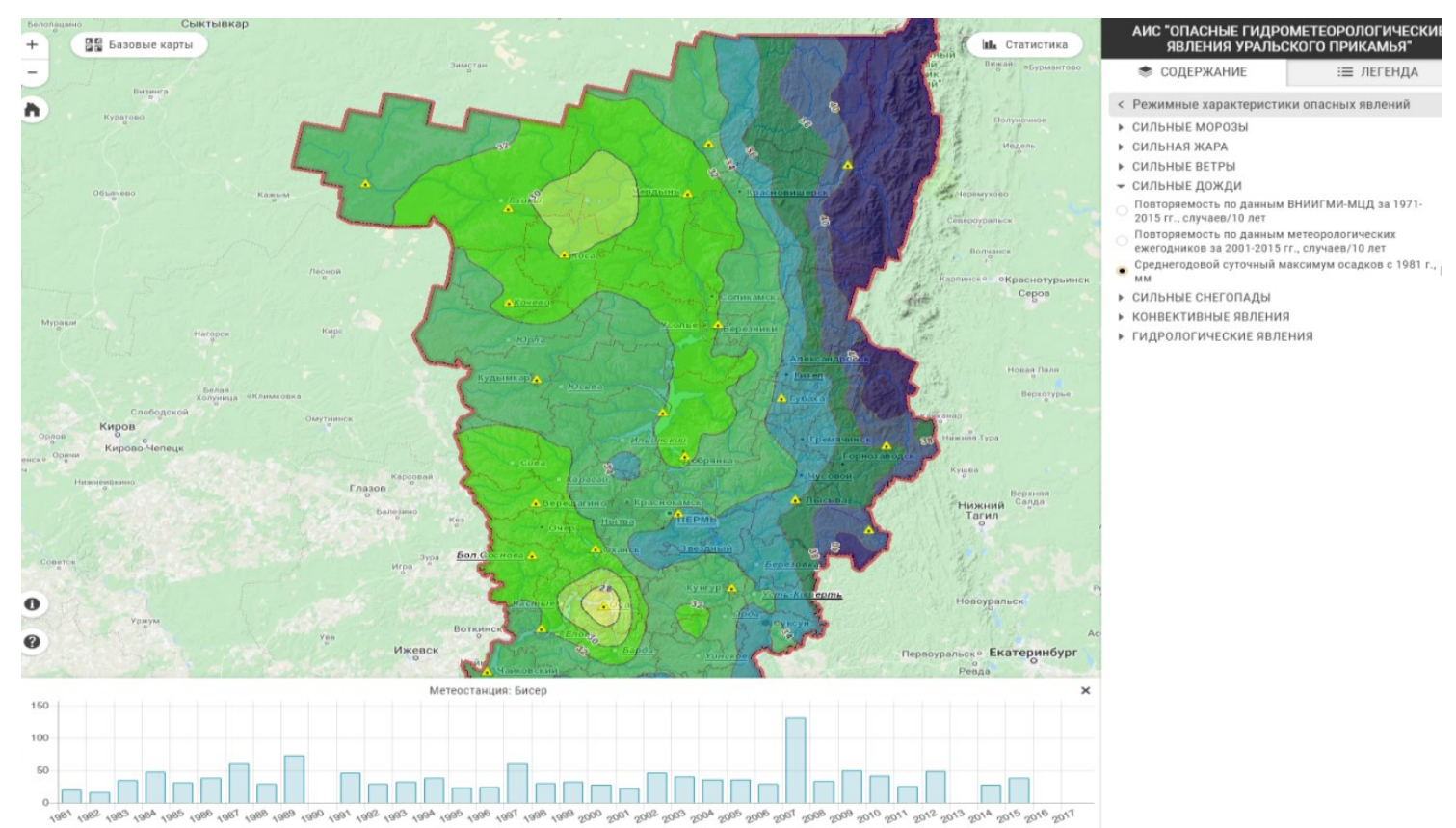

Рис 5. Отображение тематических карт и многолетних рядов климатических данных в АИС «ОГМЯ Уральского Прикамья»

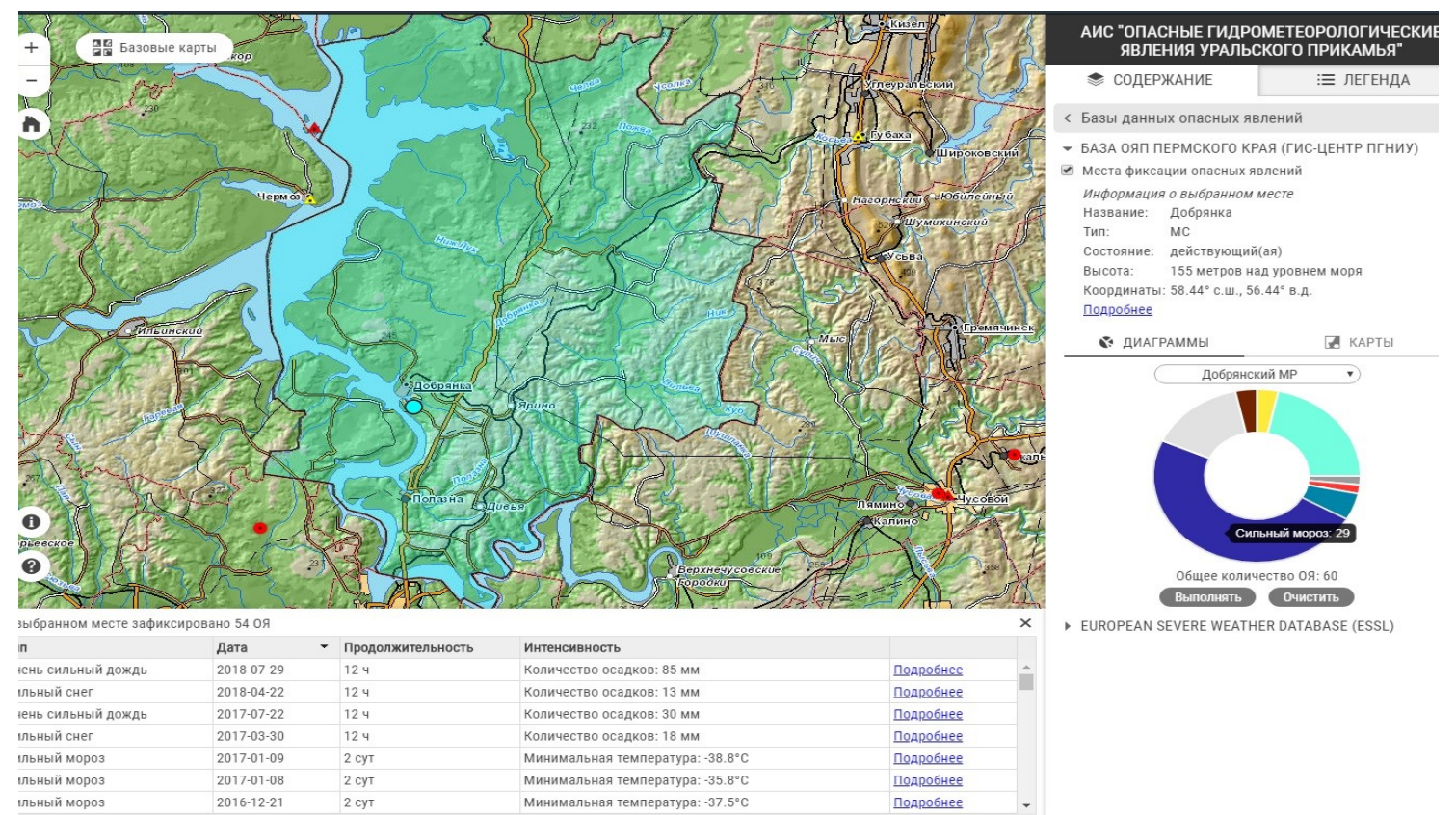

Рис 6. Просмотр информации о случаях опасных явлений в АИС

летние данные о характерных последствиях ОГМЯ на территории Пермского края - лесных пожарах, ветровалах и наводнениях, которые сгруппированы в 6 тематических слоев.

Паводкоопаснье территории - это населенные пункты, подверженные риску затопления, обычно в период весеннего половодья. Зоны возможного затопления 56 паводкоопасных территорий (рис. 8) построены по детальным цифровым моделям рельефа. Чтобы отобразить зону затопления, пользователь должен выбрать в раскрывающемся списке соответствующий населенный пункт. В результате в окне карты будет показан выбранный пункт и слои зон затопления в масштабе 1:25 000. Для некоторых пунктов приве- 

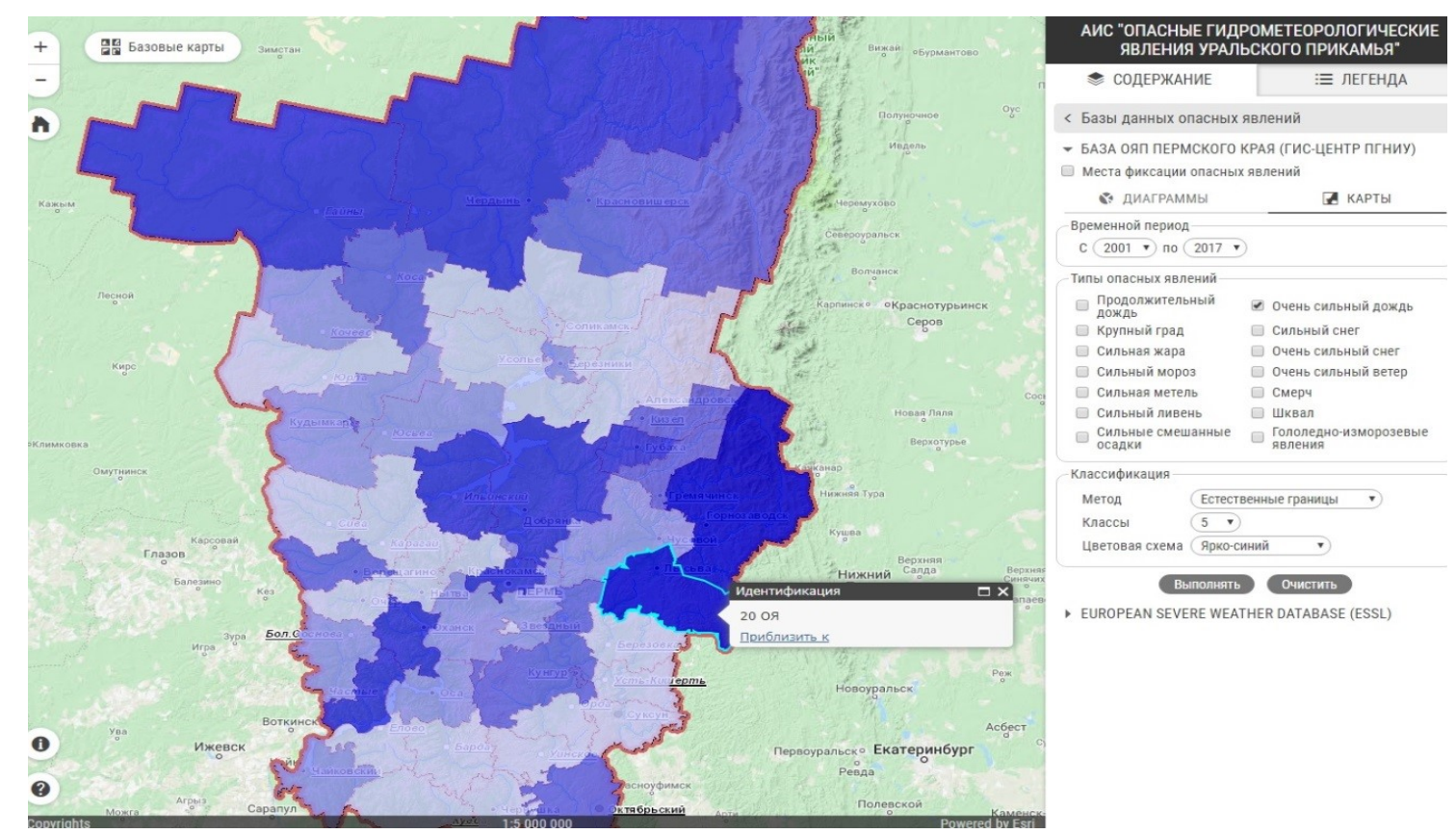

Рис. 7. Построение картограммы числа случаев очень сильных дождей за 2001-2017 г2. по районам Пермского края

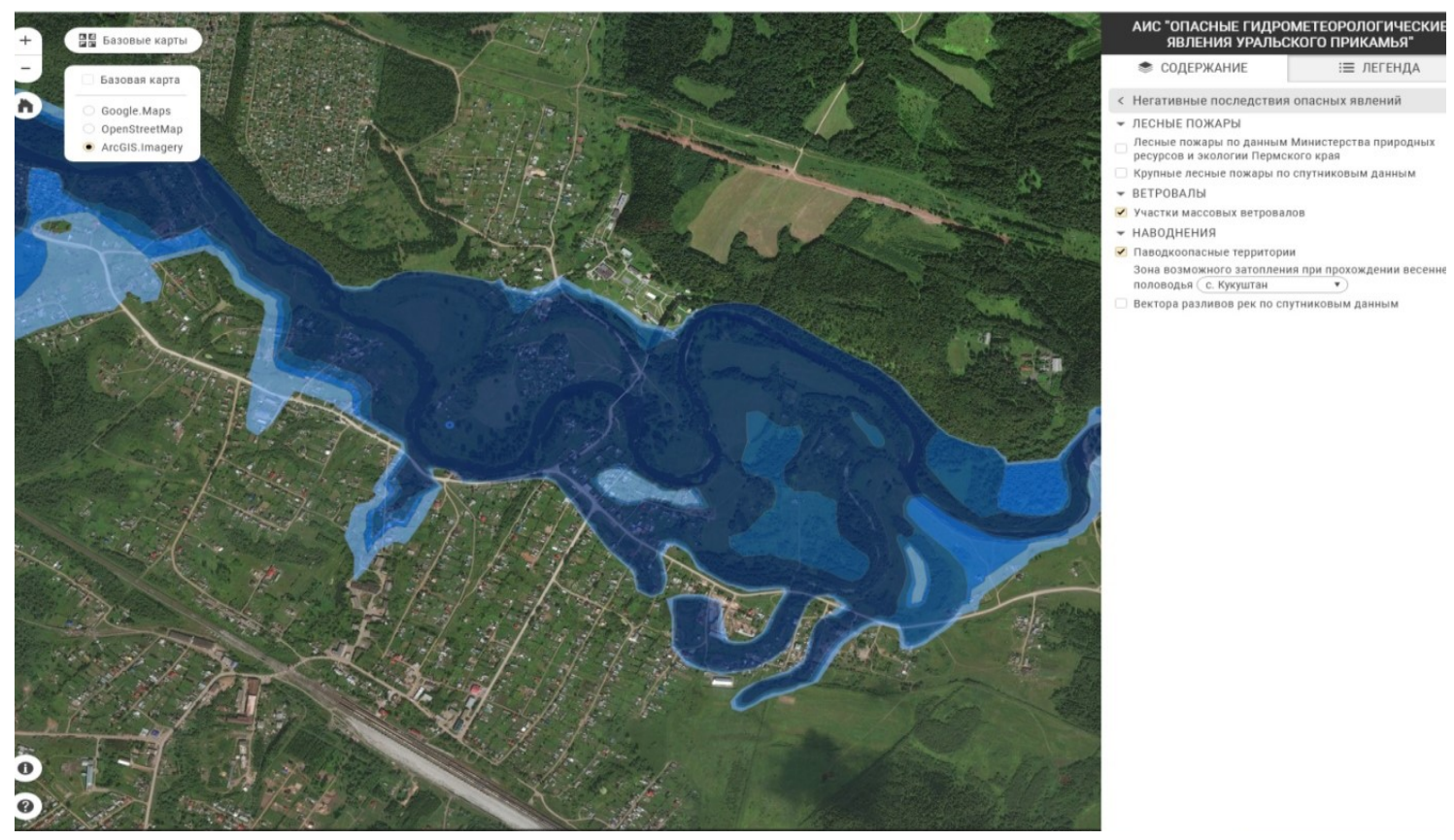

Рис. 8. Отображение зонь затопления в АИС на примере пос. Кукуштан

дены слои расчетных зон затопления с обеспеченностью $1 \%, 5 \%, 10 \%, 25 \%$.

По многолетним спутниковым данным Landsat (с 1984 г. по настоящее время) также создан векторный слой зон максимального наблюдавшегося затопления в поймах крупных рек для всей территории Пермского края. Атрибутивная таблица слоя включает сведения об использованном снимке (дата съемки, Path/Row), название реки, площадь затопления в пойме данной реки, название ближайшего гидропоста и зафиксированный уровень воды в день съемки.

Ветроваль - в данном слое представлены случаи ветровалов за период с 
1984 г. по настоящее время, выявленные по снимкам Landsat и в отдельных случаях уточненные по данным сверхвысокого разрешения (рис. 9).

Лесные пожары по данным Министерства природных ресурсов - в данном слое точками отображены места лесных пожаров, полученные по данным
Министерства природных ресурсов, лесного хозяйства и экологии Пермского края за 2010-2016 гг. Площадь пожаров отображена цветовой шкалой (рис. 10). При идентификации отображается дата возникновения пожара, его площадь, лесничество, участковое лесничество и лесные кварталы, где произошел пожар.

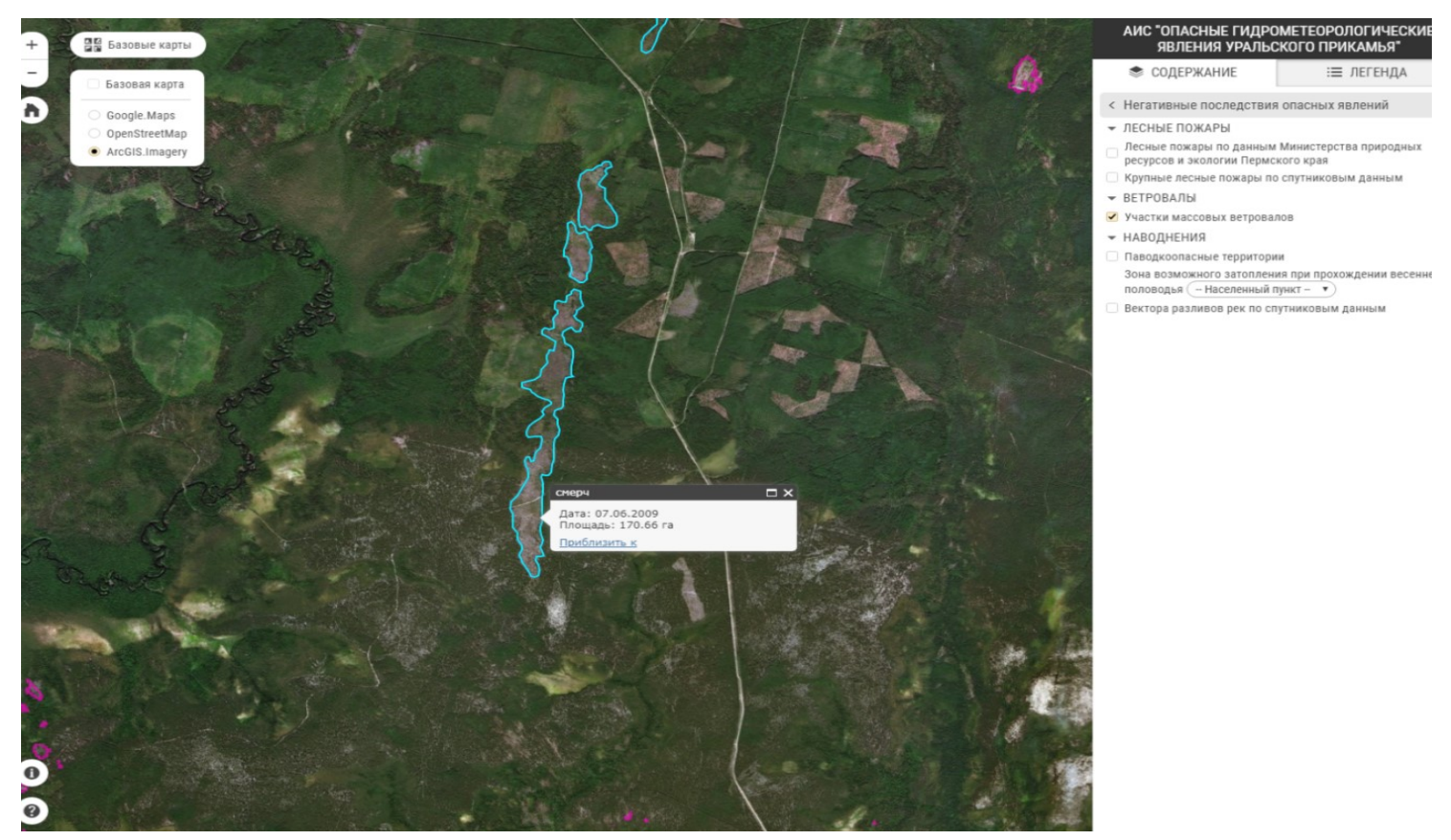

Рис. 9. Отображение контура ветровала и информации о вызвавшем его опасном явлении погоды в АИС

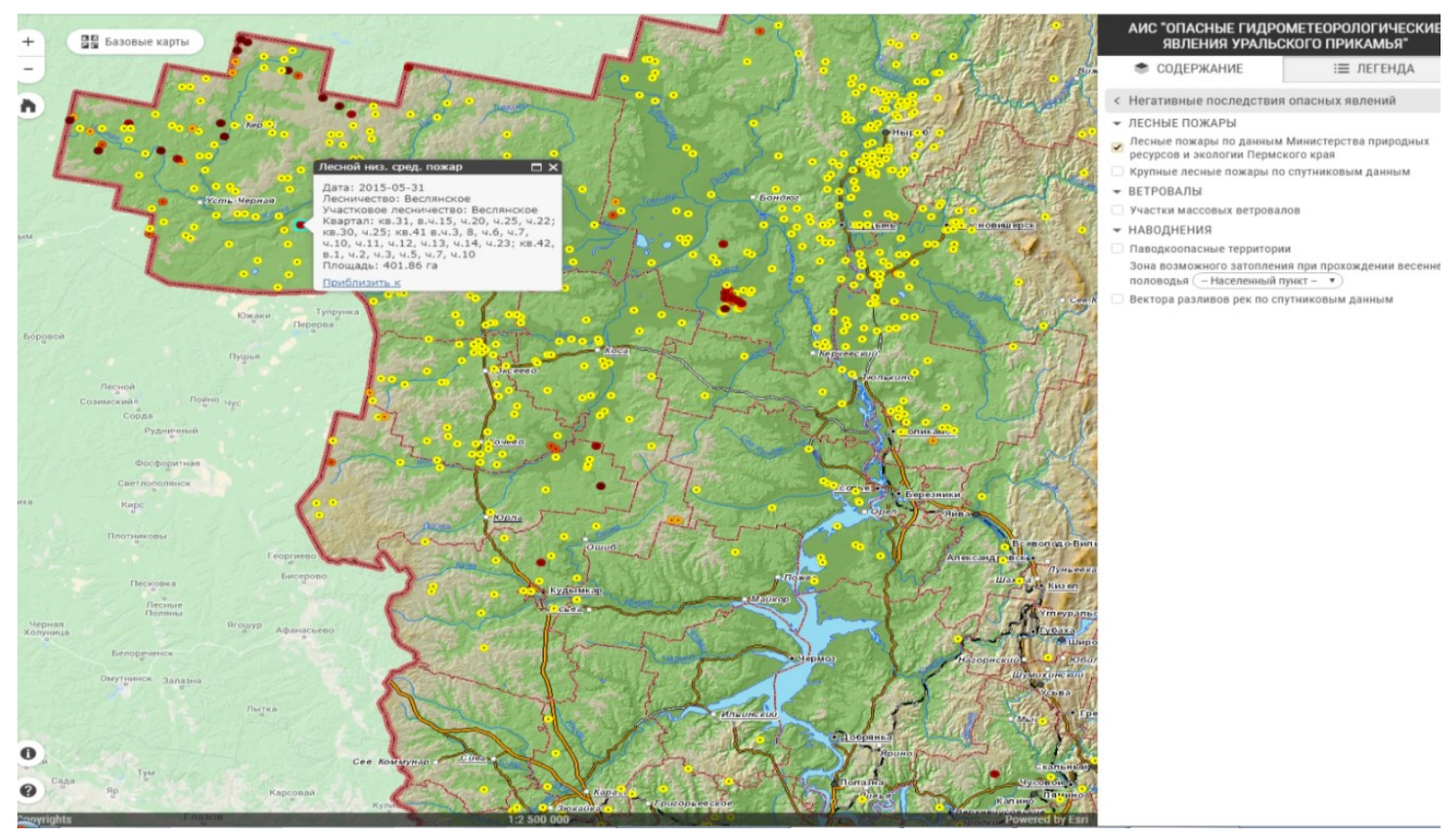

Рис. 10. Отображение случаев лесных пожаров по данным Министерства природных ресурсов Пермского края 
Крупные лесные пожары, по спутниковым данным, - в данном слое представлены случаи крупных лесных пожаров за период 1984 г. по настоящее время.

\section{Заключение}

Создание АИС «Опасные гидрометеорологические явления Уральского Прикамья» стало возможным на основе синтеза классических подходов в области атласного картографирования, современных технологий создания картографических веб-сервисов, а также результатов многолетних исследований в области мониторинга ОГМЯ. Разработанная АИС соответствует основным критериям высшего типа электронных атласов, предложенным ведущими российскими научными школами в области атласного картографирования. Подходы к проектированию, созданию и информационному наполнению АИС являются универсальными и могут быть использованы для любых регионов со сходными природно-климатическими условиями. Полученные результаты также могут использоваться в системе поддержки принятия решений в облас- ти управления рисками возникновения ЧС природного характера.

АИС может быть использована как справочно-информационный ресурс о современных климатических условиях Пермского края и характерных для региона опасных гидрометеорологических явлениях. Ее потенциальными пользователями являются лица и организации, ведущие деятельность в области инженерно-экологических изысканий, а также в других сферах, где требуется получение актуальной справочной информации о климатических условиях Пермского края.

Практическое значение имеют и отдельные опубликованные в АИС картографическое слои и наборы данных. Например, многолетние данные о лесных пожарах и ветровалах, а также карты подверженности лесов возникновению пожаров и ветровалов могут использоваться для решения задач лесохозяйственного планирования. Аналогичные работы ранее уже проводились в интересах крупнейшего арендатора лесных участков в Пермском крае ОАО «Соликамскбумпром».

\section{Библиографический список}

1. Абдуллин P.К., Шихов А.Н. Математико-картографическое моделирование пространственновременного распределения опасных явлений погоды // Геодезия и картография. -2017 . - №2 - С. 26-32.

2. Абдуллин Р.К., Шихов А.Н. Синтетическое картографирование опасных метеорологических явлений на региональном уровне // Геодезия и картография. - 2017. - №8. - С. 39-48.

3. Атлас природных и техногенных опасностей и рисков чрезвычайных ситуаций в Российской Федерации / под общ. ред. С.К. Шойгу. - М., Дизайн. Информация. Картография, 2005. - 270 с.

4. Батуев А.Р., Ермошин В.В., Конева И.В., Лопаткин Д.А., Петрищев В.П. Азиатская Россия: от серии карт к атласной информационной системе // Атласное картографирование: традиции и инновации: Материалы Х науч. кон. по тематической картографии. - Иркутск. 2015, - С. 5-8.

5. Пьянков С.В., Шихов А.Н., Абдуллин Р.К. Атлас опасных гидрометеорологических явлений Уральского Прикамья. - Пермь: Перм. гос. нац. иссл. ун-т, 2016. - 116 с.

6. Сваткова Т.Г. Атласная картография. М., Аспект Пресс, 2002. 203 с.

7. Тикунов B.C., Яблоков B.M. Атласная информационная система для Байкальского региона // ИнтерКарто/ИнтерГИС: материалы междунар. конф. - 2013. - Т. 1(19). - С. 197-202.

8. Тимонин С.А. Атласная демографическая информационная система России: автореф. дис. ... канд. геогр. наук. 25.00.33. - М., 2013. - 26 с.

9. Яблоков B.M., Тикунов В.С. Принципы создания атласной информационной системы на базе Интернета для устойчивого развития территории // Вестник Московского ун-та. Сер. 5. География. 2016. - № 1. - C. 29-38.

10. Boruff B.J., Easoz J.A., Jones S.D., Landry H.R., Mitchem J.D., Cutter S.L. Tornado hazards in the United States // Climate Research. - 2003. - Vol. 24. - P. 103-117.

11. Groenemeijer P., Kuhne T. A Climatology of tornadoes in Europe: results from the European Severe Weather Database // Monthly Weather Review. - 2014. - Vol. 142. - P. 4775-4790. 
12. Ormeling F. Functionality of Electronic School Atlases // Seminar on Electronic Atlases II, ICA Proc. on National and Regional Atlases. - Prague. -1996. - P. 33-39.

13. Shi P.J. Karsperson R. World Atlas of Natural Disaster Risk. - Heidelberg: Springer. - 2015. - 368 p.

\title{
ATLAS WEB MAPPING OF HAZARDOUS HYDROMETEOROLOGICAL EVENTS IN THE URAL PRIKAMYE REGION
}

\author{
A.N. Shikhov, R.K. Abdullin \\ Perm State National Research University
}

The paper presents the designing and development of the Atlas Information System (AIS) of hazardous hydrometeorological events (HHME) in the Ural Prikamye region. AIS integrates classic mapping approaches and modern web mapping service technologies. AIS information basis includes several data sources, both ground-based and satellite observations. The basic techniques and algorithms for mapping of HHME spatiotemporal distribution and the main AIS content are briefly described. Examples are provided of periodicity and intensity mapping of various HHME types, as well as zoning results of the study area in terms of prevailing types of hazardous weather events. The AIS core functionality is considered, including various techniques of data visualization, connection to external databases, search and query generation, building of cartograms and structural diagrams. AIS is published in open access as cartographic web map service (http://ais.maps.psu.ru). The main result of the project for the Perm region is the development of the unique reference and information cartographic resource on the current climatic conditions of the region, its typical HHME, their spatiotemporal distribution, as well as HHME-related damage.

Keywords: hazardous hydrometeorological events, atlas mapping, atlas information system, Ural Prikamye region.

\section{Сведения об авторах}

Шихов Андрей Николаевич, Кандидат географических наук, доцент кафедры картографии и геоинформатики Пермского государственного национального исследовательского университета (ПГНИУ), 614990, г. Пермь, ул. Букирева, 15; e-mail: and3131@inbox.ru

Абдуллин Ринат Камилевич, Кандидат географических наук, доцент кафедры картографии и геоинформатики, ПГНИУ, 614990, г. Пермь, ул. Букирева, 15; e-mail: rinaha-26@mail.ru 